\title{
Idiotypic Vaccination: Still a Unique form of Cancer Immunotherapy for Follicular Lymphoma after 20 Years
}

\author{
Susana Inogés ${ }^{1,2}$, Ascensión López-Díaz de Cerio ${ }^{1}$, Helena Villanueva ${ }^{1}$, Fernando \\ Pastor $^{1}$, Mario Martínez Soldevilla ${ }^{1}$, Elena Soria ${ }^{1}$ and Maurizio Bendandi ${ }^{1,2}$ \\ ${ }^{1}$ Lab of Immunotherapy, Oncology Division, Center for Applied Medical Research, University of \\ Navarra Hospital Pamplona, Spain \\ ${ }^{2}$ Immunotherapy Program, Cell Therapy Area, University of Navarra Hospital, Pamplona, Spain \\ Correspondence should be addressed to: Maurizio Bendandi; mbendandi@unav.es
}

Received 2 January 2013; Accepted 12 February 2013; Published 29 May 2013

Academic Editor: Tomáš Büchler

Copyright (c) 2013 Susana Inogés, Ascensión López-Díaz de Cerio, Helena Villanueva, Fernando Pastor, Mario Martínez Soldevilla, Elena Soria and Maurizio Bendandi. Distributed under Creative Commons CC-BY 3.0

\begin{abstract}
Idiotypic vaccination for folicular lymphoma induces a tumor-specific immune response which may kill tumor cells in vivo and prevent tumor relapse in patients. However, being based on a personalized vaccine against a person's own tumor, large scale randomized studies have produced contradictory results. The objective of this review is to define what an idiotype is and to outline the major results of twenty years of clinical research on idiotypic vaccination. We first identified the major proofs of principle obtained by its use between 1992 and 2006, focusing on both our and others' contributions. Then, we analyzed the results of randomized clinical trials, which have become available ove the last five years, and provided some of our most recent and original data.
\end{abstract}

A combination of immunological methods should be employed for proper interpretation of immune response following idiotypic vaccination. We describe some of the methods used to measure immune responses and identify tumor idiotype sequences. Some of the older methods (e.g. ELISA) may, in some instances, be misleading, and should be validated using different methods (e.g. flow cytometry). Moreover, patients who relapse years after the end of the vaccination schedule, may have undergone changes in tumor idiotype tumor idiotypes that have undergone substantial changes and is advisable to test the tumor clone at relapse to ascertain it.

While idiotypic vaccination has provided proof-of-principle of effectiveness, the data necessary for regulatory approval has yet to be generated. Therefore, better designed, confirmatory clinical trials of idiotypic vaccination are necessary.

Keywords: Idiotypic vaccination, immunoglobulin, follicular lymphoma and relapse. 


\section{Introduction}

From an operational standpoint, cancer immunotherapy consists in harnessing the power of the immune system and directing it towards the killing of tumor cells in vivo. As straightforward as this statement may sound, the term cancer immunotherapy remains as vague as the content of Pandora's box. In fact, it neither clarifies what immune system is being considered nor what different types of cancer are being targeted or which components of the immune system are being exploited.

While most cancer immunotherapies are developed within an autologous setting, it has to be remembered that the riskiest and yet most efficicacious immunotherapeutic strategy to date is still allogeneic stem cell transplantation (Kolb 2008). This approach is employed almost exclusively as an attempt to cure certain hematological malignancies, while its use against solid tumors is negligible. Moreover, the development of cancer immunotherapies has been extremely uneven among diverse types of cancer. For instance, idiotypic vaccination for lymphoma has cleared all proof-of-principle hurdles over two decades but has yet to achieve regulatory approval (Bendandi 2009), while sipuleucel-T has been approved for the treatment of certain prostate cancer patients without such a stringent proof-ofprinciple validation (Kantoff et al. 2010). $\mathrm{Be}$ as it may, it is not clear whether the whole immune system should be galvanized by cancer immunotherapy, or whether specific humoral or cellular responses should be induced depending on the type of tumor being targeted.

\section{Passive and Active Immunotherapy of Cancer}

Passive and active immunotherapies are concepts that bring to mind the respective, traditional use of immune sera and vaccines against infectious diseases. However, when applied to cancer treatment, such concepts need to be revisited.
Nowadays, passive immunotherapy against cancer mostly consists of the use of one or more monoclonal antibodies targeting antigens shared by both tumor and normal cells (i.e. tumor-associated antigens) (Weiner, Surana \& Wang 2010). Therefore, although they differ from chemotherapy agents in the way they kill tumor and normal cells, they are similar in their nonselectivity. The fore-runner of all these antibodies is rituximab, which has revolutionized the way we currently treat most B-cell malignancies, by targeting all cells expressing the CD20 surface molecule (Maloney et al. 1997).

\section{The Tumor Immunoglobulin: The Paradox of a Useless Antibody and Useful Antigen}

Many B-cell malignancies, particularly most B-cell lymphomas, consist of clonal expansions of cells all expressing the same clonal immunoglobulin on their surface (Stevenson 1975). No other normal B cell shares exactly the same immunoglobulin (Stevenson 1975). Thus, the clonal, tumorspecific immunoglobulin harbors antigenic determinants that are not found in any other immunoglobulin of the same patients. As a consequence, each tumor cell displays on its surface an immunoglobulin with specific epitopes that can be targeted by immunotherapy without interfering with the normal functioning of normal B cells.

It is worth observing that this perspective is not what we usually adopt when considering the health implications of immunoglobulins. In most if not all cases, we think of an immunoglobulin as an antibody whose natural function is to recognize and bind to an antigen. In contrast, when it comes to active immunotherapy against lymphoma, the clonal immunoglobulin becomes the target, not the tool. As target, it is considered as a collection of antigens (Bendandi 2000). 


\section{Idiotopes and Allotopes: The Idiotype as a Patient- and Tumor-Specific Antigen}

When considering any immunoglobulin, including the tumor immunoglobulin as an antigen rather than as an antibody, two groups of epitopes are encountered: idiotopes and allotopes. Allotopes are mostly located in the heavy and light chain constant regions. They are recognized as foreign by a recipient because of their presence in the immunoglobulin of the donor but not of the recipient. The differences between donor and recipient allotopes are of no functional significance (Bendandi 2000). In contrast, idiotopes are located in the hypervariable regions of the immunoglobulin variable domain, and are recognized as foreign because they do not induce self tolerance, since their small quantity present in the body is insufficient to induce self-tolerance. However, the differences between donor and recipient idiotopes may be functionally relevant in the context of $\mathrm{B}$ cell function regulation (Bendandi 2000). It is also important to remember that idiotopes and the complementarity-determining regions (CDRs), the most hypervariable portions of the immunoglobulin's variable regions, do not overlap and are not synonymous. Idiotopes serve as antigen for other antibodies, while the CDRs are the most refined tools by which an immunoglobulin recognizes an antigen (Baskar, Kobrin \& Kwak 2004).

The whole collection of idiotopes to be found within the same immunoglobulin is termed the idiotype. Inherently, the idiotype is a B-cell clone-specific antigen, which in a malignant clone becomes a tumor-specific antigen (Bendandi 2000).

\section{Idiotype, or Anti-Idiotype Vaccines?}

Confusion may arise from reading the scientific literature which variously cites idiotype and anti-idiotype vaccines. This unnecessary confusion stems from a lack of uniformity in the nomenclature used. Authors referring to idiotype vaccines imply that the vaccine core administered to the patients carries the tumor idiotype. In contrast, those referring to anti-idiotype vaccines infer that the target of vaccination is the idiotype displayed on the tumor cells. In that respect, the terms are used similarly to malaria or anti-malaria vaccines in the context of parasitic infection.

Idiotypic vaccination (Bendandi 2009) for follicular lymphoma (Bendandi 2008) is an experimental type of active immunotherapy based on the fact that the tumor cells of most patients express a clonal immunoglobulin on the cell surface. The clinical aim of this therapeutic approach is to prevent disease recurrence rather than induce tumor shrinkage. As such, it is better used in patients already with a complete, or very good partial response obtained with standard therapy. Idiotypic vaccination aims at impeding tumor relapse or progression by eliciting a polyclonal humoral and/or cellular response capable of targeting the idiotype even when it partly changes overtime due to somatic mutations (Bendandi 2009).

\section{From Tumor Idiotype to Idiotype Vaccine}

Over the last twenty years, most clinical trials of idiotypic vaccination have been conducted in patients with follicular lymphoma. Until recently, the only way the tumor idiotype could be reproduced in vitro was with use of hybridoma technology (Rodriguez-Calvillo et al. 2004). However, recombinant technology is being increasingly used to reduce production costs, labour and process duration (Bendandi 2009). Irrespective of the methodology used, the primary source for identifying the tumor idiotype remains the tumor cell that features it. The typical vaccine formulation consists of the tumor idiotype (the antigen) conjugated with keyhole limpet hemocyanin (KLH) (an immunogenic carrier) and co-administered with granulocyte-macrophage colonystimulating factor (GM-CSF) (an immunological adjuvant) (Bendandi 2009). (See schema in figure 4) 


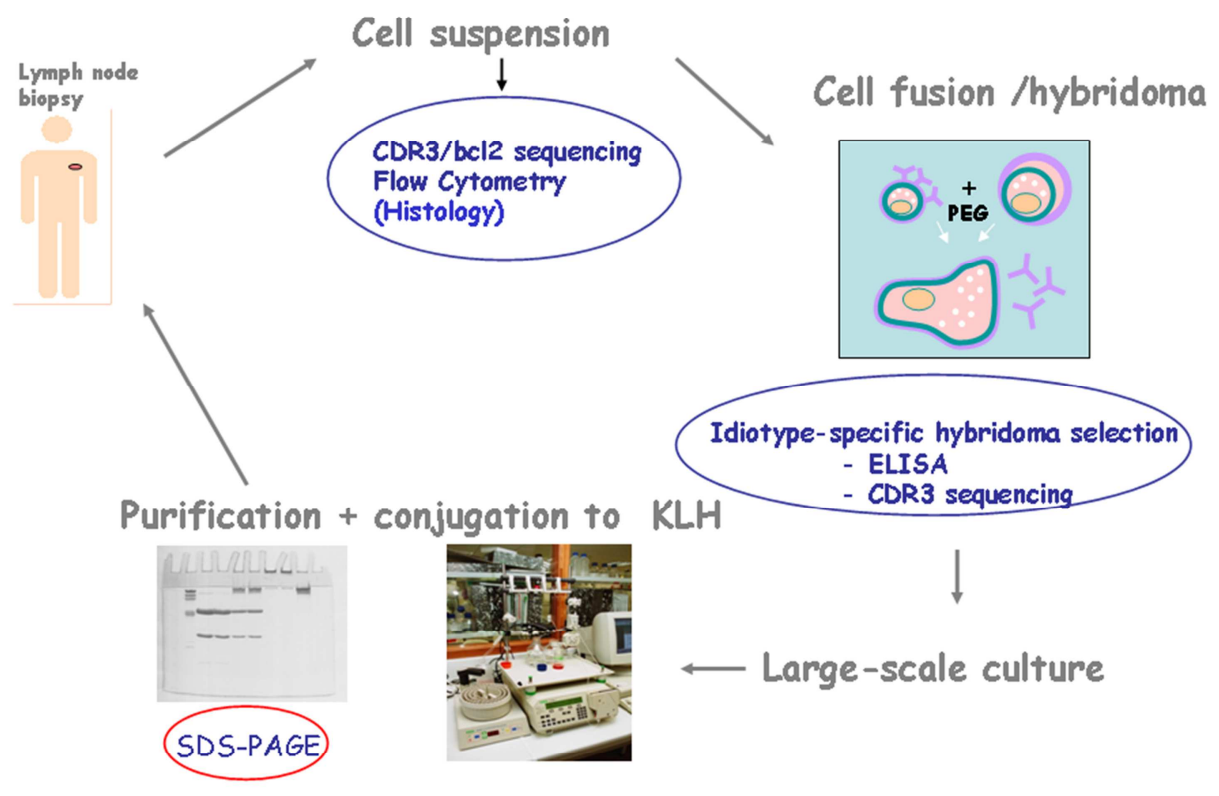

Figure 4: The Byopsed Lymph Node Tissue is Disgregated into a Cell Suspension. The CDR3 Region and Bcl-2 are Sequenced and Flow Cytometry Analyses are Performed. The Hybridome Cell is Generated by Cell Fusion and Idiotype-Specific Hybridomas are Selected Based on ELISA and CDR3 Sequencing. The Idiotype-Specific Hybridomas are Large-Scaled Cultured to Ultimately Purify the Idiotype. Once the Tumor Idiotype is Purified, it is Subsequently Conjugated with Keyhole Limpet Hemocyanin (KLH) and CoAdministered with Granulocyte-Macrophage Colony-Stimulating Factor (GM-CSF).

\section{Industrial Production of Personalized Vaccines}

The clinical trials which over the years have provided solid proof-of-principle of the potential effectiveness of idiotypic vaccination in follicular lymphoma patients did not use idiotype conjugates produced as an industrial endeavor. Instead, the conjugates were produced using good manufacturing and good clinical practice within specialist academic laboratories. However, for regulatory approval, largescale, reliable production methods are required. Establishing these methods require substantial private investments embodied by the establishment of independent companies such as Biovest, Genitope, Favrille and Icon Genetics. While the basic vaccine formulation has not changed, the way the idiotype is produced has. Biovest has remained faithful to hybridoma technology leading to products that have established all three proofs-ofprinciple: biological efficacy, clinical efficacy and clinical benefit (Bendandi 2009, Villanueva et al. 2011).In contrast, Genitope, Favrille and Icon Genetics have switched to recombinant technology, with the idiotype being ultimately produced by mammalian, insect and plant cells, respectively (Bendandi 2009, Bendandi et al. 2010).

\section{Clinical Trials and Further Development}

Idiotype vaccines are the first type of human cancer vaccines to clear the proofof-principle hurdles of biological efficacy (Kwak et al. 1992), clinical efficacy (Bendandi et al. 1999) and clinical benefit (Inoges et al. 2006) in humans. Some patients do indeed respond to vaccination by mounting a tumor idiotype-specific immune response (Kwak et al. 1992). This vaccine-induced, idiotype-specific immune 
response leads to clearance of tumor cells in vivo (Bendandi et al. 1999) and longer disease-free survival of patients with such a response (Inoges et al. 2006).

Unfortunately, three recent phase-III, randomized clinical trials have failed to achieve their main clinical endpoints (Timmerman et al. 2009a, Freedman et al. 2009, Schuster et al. 2011) and, consequently, to failure of the products concerned to obtain regulatory approval (Bendandi 2009). In two of those trials, (Freedman et al. 2009, Timmerman et al. $2009 b$ ) no significant difference in diseasefree survival was observed between patients receiving their customized vaccine and those receiving the control substance (Freedman et al. 2009). However, the study designs used may have accounted for the failure of the trials to demonstrate efficacy for the idiotype vaccines concerned (Bendandi 2009, Bendandi 2006). The third clinical trial showed a statistically, barely significant difference in relapse-free survival in favour of the vaccine (Schuster et al. 2011). Disappointingly, it failed to enroll more than two thirds of the target number of patients. While the results provide some evidence for clinical benefit of idiotypic vaccination (Inoges et al. 2006), they are not conlcusive. One or more new trials with positive results will be required for regulatory approval of the product (Bendandi 2009). Currently, the sole ongoing clinical trial of an idiotype vaccine is a phase-I study aiming at establishing the safety and tolerability of a recombinant idiotype vaccine produced in tobacco plants (Bendandi et al. 2010).

\section{Idiotope Changes}

Changes in the tumor-specific idiotype of a follicular lymphoma over time include both silent and replacing somatic mutations (Raffeld et al. 1985, Meeker et al. 1985), as well as codon insertions/deletions (Kobrin, Bendandi \& Kwak 2001). Similar changes have been reported for other B-cell malignancies (Heirman et al. 1990, Klapper et al. 2006). It has also been speculated that anti-idiotype therapy with monoclonal antibodies might exert a strong enough selective pressure on the tumor cells to provoke a tumor-specific immunoglobulin isotype switch within a few months of such 'passive' immunotherapy (Davis et al. 1998). This isotype switch, that is the selection of a gamma to replace a mu heavy-chain, would happen within the same original tumor clone, giving rise to a tumor subpopulation which would coexist with it (Davis et al. 1998). Based on all these observations, we recently decided to ascertain what happened to the idiotype of our follicular lymphoma patients relapsing after undergoing idiotypic vaccination. If the idiotype changes substantially in the relapsed tumor, the immune response induced by a previous vaccination, though in principle polyclonal, may lose its ability to exert tumor control and a new vaccine may be required. In the opposite case, the original vaccine may still be used but may feature a reduced o capacity to induce an idiotype-specific immune response actually relevant to the modified tumor idiotype. As most of the patients enrolled in our idiotype vaccine clinical trials were from other centers in Spain and other countries, only occasionally did we receive material from subsequent lymph node biopsies obtained in those places, typically years after the last vaccination was administered at our institution. This allowed us to compare idiotype sequences before and after vaccination in five such cases (Inoges et al. 2006, Inoges et al. 2009).

In four of the five cases, the idiotype sequences from the relapse material after vaccination was identical to the sequences obtained years earlier from the original lymph nodes whose single-cell suspensions had been used for vaccine production. In the fifth case, in what is to the best of our knowledge the first-in-man observation at least for patients with lymphoma, while the original tumor idiotype was found on an IgM antibody molecule, at relapse it was found on an IgG antibody molecule. Interestingly, a lambda light chain was present at both timepoints. These observations were confirmed by both immunophenotype and sequencing data. CDR2 and CDR3 were sequenced from both heavy and light chains of the tumorspecific, idiotype-bearing, clonal immunoglobulins as previously described 
(Bendandi et al. 2001), employing the same family-specific primers that we routinely employ for tumor idiotype fingerprinting, on tumor clones obtained before and after vaccination. However, given the gross discrepancy between the sequences of the tumor-related immunoglobulin heavy chain at the two timepoints, we also designed patient-specific primers covering all possible isotype combinations. In detail, we designed patient-specific primers derived from the old tumor IgM idiotype sequence (Figure 1A) and used them to possibly identify remnants of the old IgM immunoglobulin-bearing clone in the more recent tumor single-cell suspension. Similarly, we also designed patient-specific primers derived from the new tumor IgG idiotype sequence (Figure 1B) and used them to possibly identify signs of an incipient tumor clone foreshadowing the subsequent development of the new, sole or predominant, IgG immunoglobulinbearing clone in the original tumor singlecell suspension.

Much to our surprise, neither heavy chain sequence was found in the tumor singlecell suspension where it would have been at most minoritary. Moreover, despite a number of non-replacing somatic mutations, the aminoacid sequence of the tumor-specific lambda light chain remained unchanged (data not shown). Therefore, the most plausible inference is that the same disease clone had over the years undergone an isotype switch within the clonal immunoglobulin, leading to conspicuous changes in the idiotype configuration and in the glycosylation pattern (Radcliffe et al. 2007, Zhu et al. 2002) (Figure $1 \mathrm{~A}$ and 1B), without affecting the primary structure of the clonal light chain.
FR2

CDR2
FR3
CDR3

FR4

5' -LQAXGKGLEWIGNISSSENPNYQPSIRGRVTISXNTSRNXESLTINSVTTADTAVYYCARSSHRDELIRRNFDLWGQGTLVT-3'

A

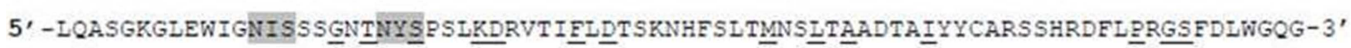

B

Figure 1.

Tumor-specific immunoglobulin's heavy chain fingerprinting at diagnosis (A) and post-vaccination relapse in the sole case analyzed in which the aminoacid sequence has changed between the two timepoints. The changes represent an overall isotype switch (see text) from IgM (A) to IgG (B). Original (A) and new (B) acquired potential glycosylation sites are highlighted. At relapse (B), individual aminoacid changes from the original IgM (A) to the new IgG (B) sequence are underlined. FR: framework región. CDR: complementarity determining región. FR and CDR indications are placed at the beginning of each of them within both sequences.

In our case, even with routine use of nested polymerase chain reactions unavailable in previous studies (Raffeld et al. 1985,
Meeker et al. 1985), we cannot speculate that idiotypic vaccination caused the isotype switch for a number of reasons. First, the change occurred years after vaccination was concluded. Second, idiotypic vaccination is an active type of immunotherapy aiming at eliciting a polyclonal response targeting several idiotopes at the same time. Third, idiotypic vaccination failed to elicit an idiotypespecific humoral immune response in this patient after the first idiotype vaccine was administered; in contrast, an idiotypespecific humoral immune response was elicited by the second idiotype vaccine customized according to the relapse idiotype sequence. Fourth, the tumorspecific heavy chain detected at relapse was not present in the original diagnosis specimen, while the tumor-specific heavy 
chain detected at diagnosis was not present in the relapse specimen. Moreover, the primary structure of the tumor-specific light chain never changed. These facts seem to indicate that, over the years, the same tumor clone, never eradicated, spontaneously underwent the heavy chain switch, rather than supporting the possible co-existence of the two isotopes. Interestingly, one of the acquired potential glycosylation sites was maintained, while the location of another had changed (Figure 1).

\section{Immune Responses Elicited by Idiotypic Vaccination}

It is not known whether both a humoral and cellular immune response induced by vaccination and specific for the idiotype are necessary for achieving clinical benefit for the patient (Bendandi 2009). Besides, whenever we succeed in confirming the former, the existence of the latter is postulated, at least in terms of T-cell helper activity elicited by the vaccine (Galon et al. 2006). Another problem that has not been solved yet is which tests should be considered the gold standards. For two decades, a positive anti-idiotype humoral response, that is the detection of vaccineinduced, idiotype-specific antibodies in a patient's post-vaccine serum, has always been associated with a positive ELISA test for tumor-specific post-vaccine sera from the same patient (Inoges et al. 2010, Inoges et al. 2011b). As we shall note below, the ELISA test alone may not be always sufficient for same cases. Even more complicated is the detection of a cellular immune response, what is the demonstration of $\mathrm{T}$-cell responses specific for the idiotype and/or the tumor, and attributable to the vaccination. None of the many tests available has ever been validated to be the most meaningful and reproducible (Inoges et al. 2006, Inoges et al. 2010, Inoges et al. 2011b).
In most patients with a vaccine-induced, idiotype-specific, humoral response, the issue of specificity is not controversial since the post-vaccine serum antibodies recognize the patient- and tumor-specific idiotype but not isotype-matched, negativecontrol idiotypes, also termed as irrelevant lymphoma idiotypes. However, other patients mount a vaccine-induced, idiotype-non-specific humoral response instead, with their post-vaccine serum antibodies recognizing isotype-matched, irrelevant lymphoma idiotypes as well. As such, they are not easily classificable as responders (i.e. with vaccine-induced, idiotype-specific humoral response) or non-responders (i.e. with no vaccineinduced humoral response), thereby making correlations between immune response and clinical effect difficult to establish. Recently, our investigation by flow cytometry of five such patients enrolled in our previous trials (Inoges et al. 2006, Inoges et al. 2009) showed that response-specificity to the patient's tumor idiotype could be demonstrated simply by using a different methodological approach. So far, the results indicate that patients with idiotype-non-specific responses could be pooled with the true responders, as there is no evidence that idiotype specificity is necessary for tumor control. This illustrates the complexity of the relationship between vaccination, immune response and disease control. of our five patients, three had apparently developed the lack of specificity over time (a representative case is illustrated in figure $2 \mathrm{~A}$ ), while in the other two cases it had been developed by the end of administration of the first five vaccine doses (a representative case is illustrated in figure 3A). Besides the standard ELISA (Kwak et al. 1992, Inoges et al. 2011b), we also undertook flow cytometric studies of each patient's tumor cells tentatively stained with the corresponding pre- and post-vaccine sera (Timmerman et al. 2009a). 
A
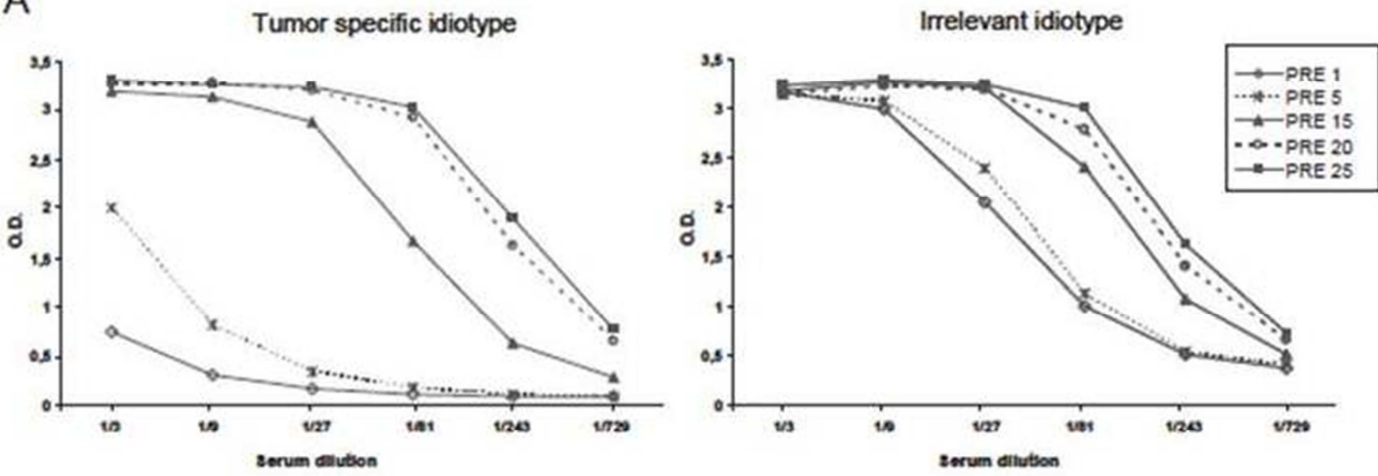

B
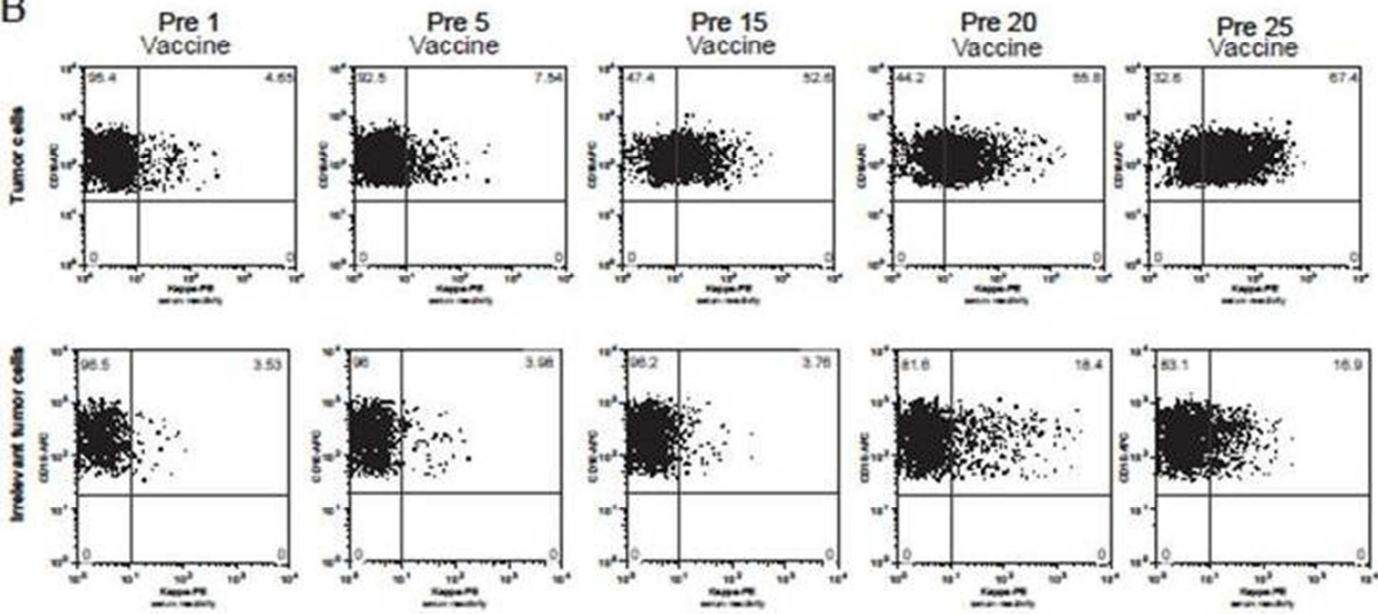

Figure 2.

ELISA (A) and flow cytometry (B) of a representative humoral response originally classified as idiotype-specific but that later became dubious. In the ELISA (A), it can be seen how the post-vaccine sera recognizes only the tumor-specific idiotype up to the fifth dose of vaccine, but when reassessed several doses later it seems to recognize other non-specific, isotype-matched tumor idiotypes. However, when the same postvaccine sera are used to stain either the original patient's tumor or the corresponding irrelevant tumor cells (B), the former are systematically stained, while the latter are not, confirming the long-term idiotype specificity of the vaccine-induced humoral response. Interestingly, a certain increase in the negative control staining is observed prior to the twentieth and the twentififth dose of vaccine, suggesting either a slow phenomenon of epitope spreading or the long-term recognition of minor antigens other than the idiotopes. For each measurement (B), the percentage of stained tumor cells is shown in the upper right quadrant. PRE-1 values indicate background signals. Abbreviations: PRE means that each serum sample was obtained from the patient immediately prior to administering the vaccination indicated by the following number. 
A

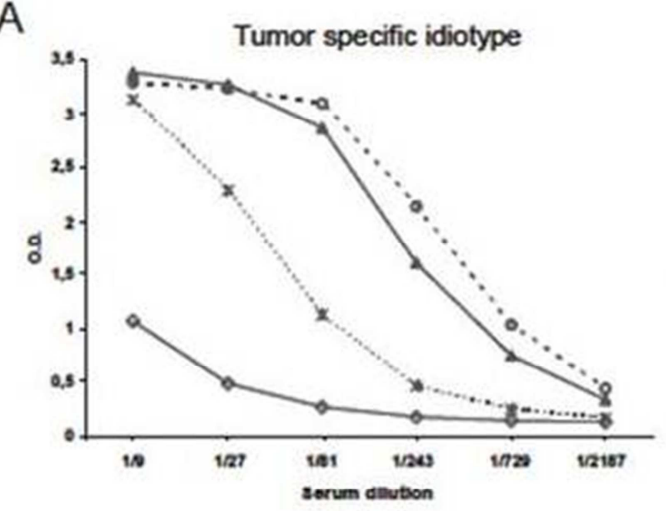

B
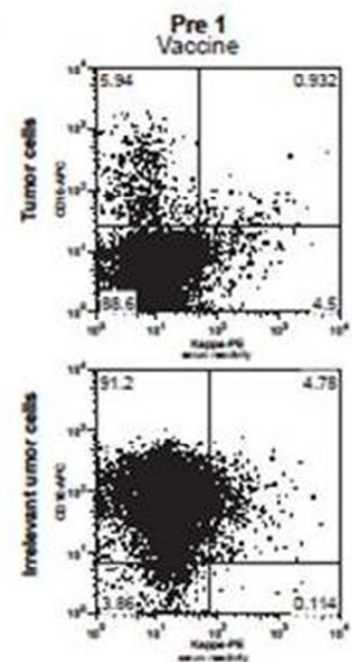
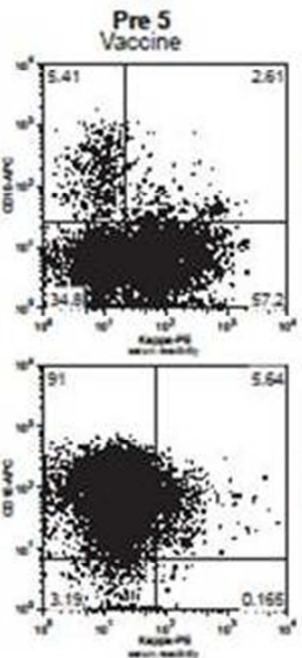
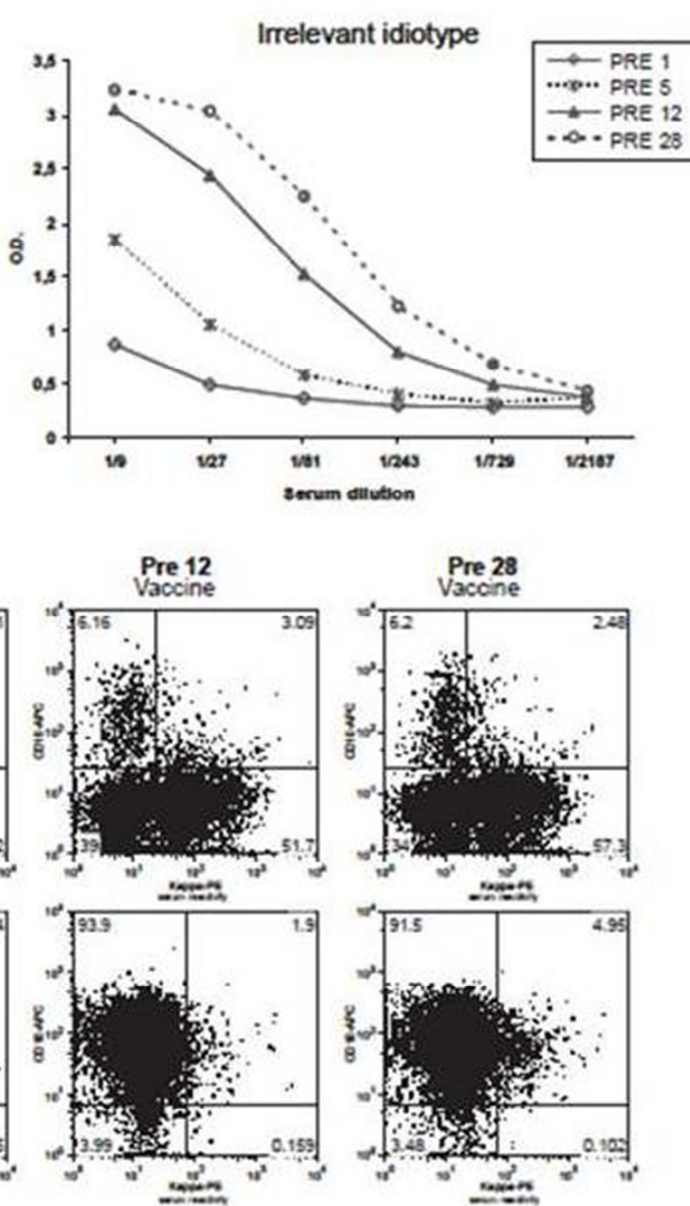

Figure 3.

ELISA (A) and flow cytometry (B) assessment of a representative humoral response originally classified as idiotypenon-specific. In the ELISA (A), it can be seen how the post-vaccine sera recognizes both the tumor-specific idiotype and an irrelevant, isotype-matched tumor idiotype. However, when the same postvaccine sera are used to stain either the original patient's tumor or the corresponding irrelevant tumor cells (B), the former are systematically stained, while the latter are not, confirming the long-term idiotype specificity of the vaccine-induced humoral response. For each measurement (B), the percentage of stained tumor cells is shown in the upper panel (specific tumor, $\mathrm{CD}^{-} 0^{-}$) and lower panel (irrelevant tumor, $\mathrm{CD} 10^{+}$) always in the right quadrant. PRE- 1 values indicate background signals. Abbreviations: PRE means that each serum sample was obtained from the patient immediately prior to administering the vaccination indicated by the following number.

Surprisingly, in all five cases, despite the evidence of lack of specificity in the humoral response as shown by ELISA (Figure 2A and 3A), the same post-vaccine sera efficiently stained the patient's tumor cells but not the negative-control tumor cells, termed as irrelevant tumor cells (Figure 2B and 3B), that is tumor cells from other lymphoma patients whose idiotypebearing immunoglobulin featured the same isotype. At most, minimal non-specific tumor cell-staining could occasionally be detected (Figure 2B) after dozens of vaccinations, raising the possibility that in a few patients epitope spreading might be a collateral action of idiotypic vaccination. There is a plausible explanation for the often controversial results obtained by ELISA and flow cytometry. In the hybridoma technology, the new hybrid cell 
contains part of mouse genes, presumably including postranslational machinery, which could affect some epitopes within the immunoglobulin produced by the hybridoma. In order to perform the ELISAs, the immunoglobulines used in detecting the anti-idiotypic response are generated by hybridoma. Therefore, this assay would show the humoral immune response against new modified epitopes generated by the hybridoma technology as well as native ones. On the other hand, in the flow cytometry assay, which is performed with the patients' tumor cells, this unspecificity is not detected (figure 3).

\section{Conclusion}

A combination of immunological methods should be employed for proper interpretation of immune response following idiotypic vaccination. When a lymphoma patient relapses after vaccination, it would be advisable to test the tumor clone at relapse to ascertain whether the idiotype has changed. Better designed, confirmatory clinical trials in idiotypic vaccination are necessary if regulatory approval is to be obtained for such vaccines. Despite the set-backs, idiotypic vaccination remains an extremely attractive approach (Inoges et al. 2009) to possibly reduce relapse of some types of lymphoma. Since every failed randomized clinical trial costed hundreds of million of dollars, careful study design is necessary, including the selection of the most suitable pre-vaccine chemotherapy regimen (Siddhartha, Vijay 2009, Zinzani et al. 2000, Rigacci et al. 2012).

\section{References}

Baskar, S., Kobrin, C. B. \& Kwak, L. W. (2004). "Autologous Lymphoma Vaccines Induce Human $\mathrm{T}$ Cell Responses against Multiple, Unique Epitopes," The Journal of Clinical Investigation, Vol. 113, No. 10, Pp. 1498-1510.

Bendandi, M. (2000). "Anti-Idiotype Vaccines for Human Follicular Lymphoma," Leukemia: Official Journal of the Leukemia Society of America, Leukemia Research Fund, U.K, Vol. 14, No. 8, Pp. 1333-1339.
Bendandi, M. (2006). "Clinical Benefit of Idiotype Vaccines: Too Many Trials for a Clever Demonstration?," Reviews on Recent Clinical Trials, Vol. 1, No. 1, Pp. 67-74.

Bendandi, M. (2008). "Aiming at a Curative Strategy for Follicular Lymphoma," CA: $A$ Cancer Journal for Clinicians, Vol. 58, No. 5, Pp. 305-317.

Bendandi, M. (2009). "Idiotype Vaccines for Lymphoma: Proof-of-Principles and Clinical Trial Failures," Nature Reviews.Cancer, Vol. 9, No. 9, Pp. 675-681.

Bendandi, M., Gocke, C. D., Kobrin, C. B., Benko, F. A., Sternas, L. A., Pennington, R., Watson, T. M., Reynolds, C. W., Gause, B. L., Duffey, P. L., Jaffe, E. S., Creekmore, S. P., Longo, D. L. \& Kwak, L. W. (1999). "Complete Molecular Remissions Induced by Patient-Specific Vaccination Plus Granulocyte-Monocyte Colony-Stimulating Factor Against Lymphoma," Nature Medicine, Vol. 5, No. 10, Pp. 1171-1177.

Bendandi, M., Marillonnet, S., Kandzia, R., Thieme, F., Nickstadt, A., Herz, S., Frode, R., Inoges, S., Lopez-Diaz De Cerio, A., Soria, E., Villanueva, H., Vancanneyt, G., Mccormick, A., Tuse, D., Lenz, J., Butler-Ransohoff, J. E., Klimyuk, V. \& Gleba, Y. (2010). "Rapid, High-Yield Production in Plants of Individualized Idiotype Vaccines for NonHodgkin's Lymphoma," Annals of Oncology: Official Journal of the European Society for Medical Oncology / ESMO, Vol. 21, No. 12, Pp. 2420-2427.

Bendandi, M., Tonelli, R., Maffei, R., Botti, S., Turi, C., Sartini, R., Inoges, S., Calvillo, M. R., Zinzani, P. L., Pession, A., Pileri, S. A. \& Paolucci, G. (2001). "Identification of the BCell Tumor-Specific Molecular Fingerprint Using Non-Radiolabelled PCR Consensus Primers," Annals of Oncology: Official Journal of the European Society for Medical Oncology / ESMO, Vol. 12, No. 10, Pp. 14791484.

Davis, T. A., Maloney, D. G., Czerwinski, D. K., Liles, T. M. \& Levy, R. (1998). "AntiIdiotype Antibodies Can Induce Long-Term Complete Remissions in Non-Hodgkin's Lymphoma without Eradicating the Malignant Clone," Blood, Vol. 92, No. 4, Pp. 1184-1190. 
De Cerio, A. L., Zabalegui, N., RodriguezCalvillo, M., Inoges, S. \& Bendandi, M. (2007). "Anti-Idiotype Antibodies in Cancer Treatment," Oncogene, Vol. 26, No. 25, Pp. 3594-3602.

Freedman, A., Neelapu, S. S., Nichols, C., Robertson, M. J., Djulbegovic, B., Winter, J. N., Bender, J. F., Gold, D. P., Ghalie, R. G., Stewart, M. E., Esquibel, V. \& Hamlin, P. (2009). "Placebo-Controlled Phase III Trial of Patient-Specific Immunotherapy with Mitumprotimut-T and GranulocyteMacrophage Colony-Stimulating Factor after Rituximab in Patients with Follicular Lymphoma," Journal of Clinical Oncology: Official Journal of the American Society of Clinical Oncology, Vol. 27, No. 18, Pp. 30363043.

Galon, J., Costes, A., Sanchez-Cabo, F., Kirilovsky, A., Mlecnik, B., Lagorce-Pages, C., Tosolini, M., Camus, M., Berger, A., Wind, P., Zinzindohoue, F., Bruneval, P., Cugnenc, P. H., Trajanoski, Z., Fridman, W. H. \& Pages, F. (2006). "Type, Density, and Location of Immune Cells within Human Colorectal Tumors Predict Clinical Outcome," Science (New York, N.Y.), Vol. 313, No. 5795, Pp. 1960-1964.

Heirman, C., Vaeremans, E., Carels, D., Theunissen, J., Van Camp, B. \& Thielemans, K. (1990). "Isotype Switch and Idiotype Variation in Hairy Cell Leukemia," Leukemia: Official Journal of the Leukemia Society of America, Leukemia Research Fund, U.K, Vol. 4, No. 12, Pp. 856-862.

Inoges, S., De Cerio, A. L., Soria, E., Villanueva, H., Pastor, F. \& Bendandi, M. (2010). "Idiotype Vaccines for Human BCell Malignancies," Current Pharmaceutical Design, Vol. 16, No. 3, Pp. 300-307.

Inoges, S., De Cerio, A. L., Villanueva, H., Soria, E., Pastor, F. \& Bendandi, M. (2011a). "Idiotype Vaccines for Lymphoma Therapy," Expert Review of Vaccines, Vol. 10, No. 6, Pp. 801-809.

Inoges, S., Lopez-Diaz De Cerio, A., Sampol, A., Nieto, J., Soria, E., Villanueva, H., Pastor, F. \& Bendandi, M. (2011b). "Stem Cell Transplant and Idiotypic Vaccination for B-
Cell Malignancies," Current Topics in Medicinal Chemistry, Vol. 11, No. 13, Pp. 1653-1660.

Inoges, S., Lopez-Diaz De Cerio, A., Zabalegui, N., Soria, E., Villanueva, H., Panizo, C., Rodriguez-Caballero, A., Suarez, L., Pastor, F., Rodriguez-Calvillo, M., Orfao, A. \& Bendandi, M. (2009). "Prolonged Idiotypic Vaccination Against Follicular Lymphoma," Leukemia \& Lymphoma, Vol. 50, No. 1, Pp. 47-53.

Inoges, S., Rodriguez-Calvillo, M., Zabalegui, N., Lopez-Diaz De Cerio, A., Villanueva, H., Soria, E., Suarez, L., Rodriguez-Caballero, A., Pastor, F., Garcia-Munoz, R., Panizo, C., Perez-Calvo, J., Melero, I., Rocha, E., Orfao, A., Bendandi, M., Grupo Espanol De Linfomas/Trasplante Autologo De Medula Oseo Study Group \& Programa Para El Estudio Y Tratamiento De Hemopatias Malignas Study Group (2006). "Clinical Benefit Associated with Idiotypic Vaccination in Patients with Follicular Lymphoma," Journal of the National Cancer Institute, Vol. 98, No. 18, Pp. 1292-1301.

Kantoff, P. W., Higano, C. S., Shore, N. D., Berger, E. R., Small, E. J., Penson, D. F., Redfern, C. H., Ferrari, A. C., Dreicer, R., Sims, R. B., Xu, Y., Frohlich, M. W., Schellhammer, P. F. \& IMPACT Study Investigators (2010). "Sipuleucel-T Immunotherapy for Castration-Resistant Prostate Cancer," The New England Journal of Medicine, Vol. 363, No. 5, Pp. 411-422.

Klapper, W., Szczepanowski, M., Heidorn, K., Muschen, M., Liedtke, S., Sotnikova, A., Andersen, N. S., Greeve, J. \& Parwaresch, R. (2006). "Immunoglobulin Class-Switch Recombination Occurs in Mantle Cell Lymphomas," The Journal of Pathology, Vol. 209, No. 2, Pp. 250-257.

Kobrin, C., Bendandi, M. \& Kwak, L. W. (2001). "Novel Secondary Ig VH Gene Rearrangement and in-Frame Ig Heavy Chain Complementarity-Determining Region III Insertion/Deletion Variants in De Novo Follicular Lymphoma," Journal of Immunology (Baltimore, Md.: 1950), Vol. 166, No. 4, Pp. 2235-2243. 
Kolb, H. J. (2008). "Graft-Versus-Leukemia Effects of Transplantation and Donor Lymphocytes," Blood, Vol. 112, No. 12, Pp. 4371-4383.

Kwak, L. W., Campbell, M. J., Czerwinski, D. K., Hart, S., Miller, R. A. \& Levy, R. (1992). "Induction of Immune Responses in Patients with B-Cell Lymphoma Against the Surface-Immunoglobulin Idiotype Expressed by Their Tumors," The New England Journal of Medicine, Vol. 327, No. 17, Pp. 1209-1215.

Maloney, D. G., Grillo-Lopez, A. J., White, C. A., Bodkin, D., Schilder, R. J., Neidhart, J. A., Janakiraman, N., Foon, K. A., Liles, T. M., Dallaire, B. K., Wey, K., Royston, I., Davis, T. \& Levy, R. (1997). "IDEC-C2B8 (Rituximab) Anti-CD20 Monoclonal Antibody Therapy in Patients with Relapsed Low-Grade NonHodgkin's Lymphoma," Blood, Vol. 90, No. 6, Pp. 2188-2195.

Meeker, T., Lowder, J., Cleary, M. L., Stewart, S., Warnke, R., Sklar, J. \& Levy, R. (1985). "Emergence of Idiotype Variants during Treatment of B-Cell Lymphoma with AntiIdiotype Antibodies," The New England Journal of Medicine, Vol. 312, No. 26, Pp. 1658-1665.

Radcliffe, C. M., Arnold, J. N., Suter, D. M., Wormald, M. R., Harvey, D. J., Royle, L., Mimura, Y., Kimura, Y., Sim, R. B., Inoges, S., Rodriguez-Calvillo, M., Zabalegui, N., De Cerio, A. L., Potter, K. N., Mockridge, C. I., Dwek, R. A., Bendandi, M., Rudd, P. M. \& Stevenson, F. K. (2007). "Human Follicular Lymphoma Cells Contain Oligomannose Glycans in the Antigen-Binding Site of the B-Cell Receptor," The Journal of Biological Chemistry, Vol. 282, No. 10, Pp. 7405-7415.

Raffeld, M., Neckers, L., Longo, D. L. \& Cossman, J. (1985). "Spontaneous Alteration of Idiotype in a Monoclonal Bcell Lymphoma. Escape from Detection by Anti-Idiotype," The New England Journal of Medicine, Vol. 312, No. 26, Pp. 1653-1658.

Rigacci, L., Puccini, B., Cortelazzo, S., Gaidano, G., Piccin, A., D'Arco, A., Freilone, R., Storti, S., Orciuolo, E., Zinzani, P. L., Zaja, F., Bongarzoni, V., Balzarotti, M., Rota-
Scalabrini, D., Patti, C., Gobbi, M., Carpaneto, A., Liberati, A. M., Bosi, A. \& Iannitto, E. (2012). "Bendamustine with or without Rituximab for the Treatment of Heavily Pretreated Non-Hodgkin's Lymphoma Patients: A Multicenter Retrospective Study on Behalf of the Italian Lymphoma Foundation (FIL)," Annals of Hematology, Vol. 91, No. 7, Pp. 1013-1022.

Rodriguez-Calvillo, M., Inoges, S., LopezDiaz De Cerio, A., Zabalegui, N., Villanueva, H. \& Bendandi, M. (2004). "Variations in "Rescuability" of Immunoglobulin Molecules from Different Forms of Human Lymphoma: Implications for Anti-Idiotype Vaccine Development," Critical Reviews in Oncology/Hematology, Vol. 52, No. 1, Pp. 17.

Schuster, S. J., Neelapu, S. S., Gause, B. L., Janik, J. E., Muggia, F. M., Gockerman, J. P., Winter, J. N., Flowers, C. R., Nikcevich, D. A., Sotomayor, E. M., Mcgaughey, D. S., Jaffe, E. S., Chong, E. A., Reynolds, C. W., Berry, D. A., Santos, C. F., Popa, M. A., Mccord, A. M. \& Kwak, L. W. (2011). "Vaccination with Patient-Specific Tumor-Derived Antigen in First Remission Improves Disease-Free Survival in Follicular Lymphoma," Journal of Clinical Oncology: Official Journal of the American Society of Clinical Oncology, Vol. 29, No. 20, Pp. 2787-2794.

Siddhartha, G. \& Vijay, P. (2009). "R-CHOP Versus R-CVP in the Treatment of Follicular Lymphoma: A Meta-Analysis and Critical Appraisal of Current Literature," Journal of Hematology \& Oncology, Vol. 2, Pp. 148722-2-14.

Stevenson, G. T. \& Stevenson, F. K. (1975). "Antibody to a Molecularly-Defined Antigen Confined to a Tumour Cell Surface," Nature, Vol. 254, No. 5502, Pp. 714-716.

Timmerman, J. M., Vose, J. M., Czerwinski, D. K., Weng, W. K., Ingolia, D., Mayo, M., Denney, D. W. \& Levy, R. (2009a). "TumorSpecific Recombinant Idiotype Immunisation after Chemotherapy as Initial Treatment for Follicular NonHodgkin Lymphoma," Leukemia \& Lymphoma, Vol. 50, No. 1, Pp. 37-46. 
Timmerman, J. M., Vose, J. M., Czerwinski, D. K., Weng, W. K., Ingolia, D., Mayo, M., Denney, D. W. \& Levy, R. (2009b). "TumorSpecific Recombinant Idiotype Immunisation after Chemotherapy as Initial Treatment for Follicular NonHodgkin Lymphoma," Leukemia \& Lymphoma, Vol. 50, No. 1, Pp. 37-46.

Villanueva, H., De Cerio, A. L., Inoges, S., Pastor, F., Soldevilla, M. M. \& Bendandi, M. (2011). "Biovaxid(R): A Customized Idiotype Vaccine for the Treatment of BCell Lymphoma," Expert Review of Vaccines, Vol. 10, No. 12, Pp. 1661-1669.

Weiner, L. M., Surana, R. \& Wang, S. (2010). "Monoclonal Antibodies: Versatile Platforms for Cancer Immunotherapy," Nature Reviews.Immunology, Vol. 10, No. 5, Pp. 317-327.

Yu, J. S., Liu, G., Ying, H., Yong, W. H., Black, K. L. \& Wheeler, C. J. (2004). "Vaccination with Tumor Lysate-Pulsed Dendritic Cells Elicits Antigen-Specific, Cytotoxic T-Cells in Patients with Malignant Glioma," Cancer Research, Vol. 64, No. 14, Pp. 4973-4979.

Zhu, D., Mccarthy, H., Ottensmeier, C. H., Johnson, P., Hamblin, T. J. \& Stevenson, F. K. (2002). "Acquisition of Potential NGlycosylation Sites in the Immunoglobulin Variable Region by Somatic Mutation is a Distinctive Feature of Follicular Lymphoma," Blood, Vol. 99, No. 7, Pp. 25622568.

Zinzani, P. L., Magagnoli, M., Bendandi, M., Gherlinzoni, F., Orcioni, G. F., Cellini, C., Stefoni, V., Pileri, S. A. \& Tura, S. (2000). "Efficacy of Fludarabine and Mitoxantrone (FN) Combination Regimen in Untreated Indolent Non-Hodgkin's Lymphomas," Annals of Oncology: Official Journal of the European Society for Medical Oncology / ESMO, Vol. 11, No. 3, Pp. 363-365. 